\title{
Active surveillance in favorable intermediate-risk prostate cancer patients: Predictors of deferred intervention and treatment choice
}

\author{
Rashid K. Sayyid, MD, MSc'; Laurence Klotz, MD, FRCSC'; John Z. Benton, BS3; Merry Ma, MD, PhD'; \\ Phillip Woodruff, RN, BIS'; Raj Satkunasivam, MD, MS ; ; Martha K. Terris, MD',5; \\ Christopher J.D. Wallis, MD, PhD, FRCSC ${ }^{*}$; Zachary Klaassen, MD, MSC ${ }^{1,5^{*}}$
}

'Section of Urology, Department of Surgery, Medical College of Georgia-Augusta University, Augusta, GA, United States; 2Division of Urology, Department of Surgery, Sunnybrook Health Sciences Centre, Toronto, ON, Canada; ${ }^{3}$ Medical College of Georgia, Augusta, GA, United States; ${ }^{4}$ Department of Urology and Center for Outcomes Research, Houston Methodist Hospital, Houston, TX, United States; ${ }^{5}$ Georgia Cancer Center, Augusta, GA, United States; ${ }^{6}$ Department of Urology, Vanderbilt University Medical Center, Nashville, TN, United States

${ }^{*}$ Co-senior authors

Cite as: Sayyid RK, Klotz L, Benton JZ, et al. Active surveillance in favorable intermediate-risk prostate cancer patients: Predictors of deferred intervention and treatment choice. Can Urol Assoc J 2022;16(1):E7-14. http://dx.doi.org/10.5489/cuaj.7272

Published online August 26, 2021

Appendix available at cuaj.ca

\section{Abstract}

Introduction: Active surveillance (AS) is increasingly used for favorable intermediate-risk (FIR) prostate cancer (PCa). Our objective was to determine oncological and sociodemographic predictors of deferred definitive therapy and decision for radical prostatectomy (RP) vs. radiotherapy (RT).

Methods: The Surveillance, Epidemiology, and End Results (SEER) Prostate with Watchful Waiting database was used to identify all FIR PCa diagnosed between 2010 and 2015 opting for AS for at least one year following diagnosis. We sought to determine predictors of treatment and treatment type using multivariable logistic regression. Results: A total of 20334 patients were identified. An annual decrease in incident FIR patients managed initially with AS between 2010 (4061) and 2015 (2947) was noted ( $p$ for trend <0.001); 17 $895(88.0 \%)$ patients underwent deferred RP and/or RT. Patients with higher baseline cancer volume and clinical stage were significantly more likely to discontinue AS. Patients of higher socioeconomic status were more likely to undergo deferred therapy, with increased odds for RT over RP. African American patients had lower odds of undergoing definitive intervention (odds ratio 0.83, $p=0.030$ ) and were significantly more likely to opt for XRT. Oncological characteristics leading to FIR classification influenced treatment choice at the time of deferred intervention: RT was treatment of choice in $86.3 \%$ and $86.0 \%$ of Gleason group 2 and prostate-specific antigen 10-20 FIR patients, respectively; 96.1\% of treated cT2b-c FIR patients opted for RP.

Conclusions: Most FIR PCa patients initially managed with AS eventually undergo deferred definitive therapy, with choice of treat- ment significantly influenced by patients' baseline oncological and sociodemographic characteristics.

\section{Introduction}

Active surveillance (AS) is currently the standard of care for very low- and low-risk prostate cancer (PCa)., ${ }^{1,2}$ This management strategy has proven its long-term oncological safety in these cohorts and simultaneously maintains patient quality of life, ${ }^{3,4}$ and thus, there has been increased interest in expanding the indications for AS to the intermediate-risk cohort. This is supported by results from the Prostate Testing for Cancer and Treatment (ProtecT) trial demonstrating that low- and intermediate-risk PCa patients managed conservatively with active monitoring had long-term PCa mortality outcomes similar to those managed with radical prostatectomy (RP) or radiotherapy (RT). ${ }^{5}$ Furthermore, a large, multinational autopsy study demonstrated that more than half of Asian men with incidental PCa at autopsy harbored evidence of Grade Group (GG) 2 disease or worse, confirming the indolent nature of a subset of this risk group. ${ }^{6}$ These findings have contributed to multiple governing bodies supporting AS use for patients with favorable intermediate-risk (FIR) PCa, ${ }^{1,2}$ defined per the National Comprehensive Cancer Network (NCCN) as predominant GG1 disease, percentage of positive biopsy cores $<50 \%$, and a single NCCN intermediate risk factor. ${ }^{7}$ These recommendations have been reflected in an increased uptake of AS for patients with intermediaterisk disease, with a recent analysis of the Surveillance, Epidemiology, and End Results (SEER) Prostate with Watchful Waiting (WW) database demonstrating that use of AS for such patients has significantly increased over time, from $3.7 \%$ in 2010 to $7.3 \%$ in $2015 .^{8}$

With the increased uptake of AS for FIR PCa patients, understanding the factors influencing the decision to discon- 
tinue AS in favor of deferred definitive intervention, as part of a shared decision-making process between the patient and physician, becomes important. Our objective was to evaluate both oncological and sociodemographic predictors of undergoing deferred definitive intervention after a period of AS, and in patients undergoing deferred intervention, choice of RP vs. RT.

\section{Methods}

\section{Patient population}

Men with NCCN FIR PCa were identified using the SEER WW database, which is a nationally representative database supported by the National Cancer Institute that captures patients with incident PCa from 18 population-based registries, accounting for approximately $30 \%$ of the U.S. population. Study patients were diagnosed with PCa between 2010 and 2015 and all underwent documented AS or WW for a period of at least one year, as per records from the treating institutions. ${ }^{9}$ Such patients did not receive definitive therapy for at least one year following diagnosis and were managed with AS or WW for at least one year following diagnosis. Thus, patients initially managed with AS or WW but who subsequently opted for definitive therapy within one year of diagnosis and those that simply deferred treatment by one year were not included in the cohort. Patients older than 80 years at time of diagnosis were excluded from our cohort, as the majority of such patients would be expected to fall under the WW category. ${ }^{10}$ Patients were not excluded if they had a prior diagnosis of another non-PCa related malignancy and were noted as such.

FIR patients were subdivided into one of three groups based on which risk factor categorized them as having intermediate-risk disease, per NCCN criteria: GG2, prostatespecific antigen (PSA) $10-20 \mathrm{ng} / \mathrm{ml}$, and cT2b-c. Each patient thus had only one intermediate risk factor and the three FIR groups were mutually exclusive.

Given the deidentified and public availability of the dataset, research ethics board approval for this study was not required by the participating institutions.

\section{Study outcomes}

The two primary study outcomes were: 1) a definitive intervention event, defined as RP or definitive RT; and 2) choice of RP vs. definitive RT among those who opted for intervention. Definitive RT includes both external beam radiotherapy and/or brachytherapy treatment. These two outcomes were each operationalized as a binary variable (yes vs. no), with time to intervention not available from this dataset.

\section{Study variables}

Patient oncological and sociodemographic variables were available at time of PCa diagnosis only. Oncological variables included: clinical T, N, and M stages, serum PSA level, Gleason score on prostate biopsy or transurethral resection of the prostate (TURP) specimens, and number of positive and sampled biopsy cores/specimens. The percent positive cores variable was calculated from the number of positive and sampled cores/specimens for each patient. Followup serum PSA levels, clinical exam, imaging findings, and repeat biopsy results were not available, and thus the trigger for discontinuing AS in favor of deferred therapy was not available.

Baseline patient-level sociodemographic variables included: year of diagnosis, age at diagnosis, race, insurance status, marital status, and SEER registry. Individual socioeconomic status (SES) was derived from the following five county-level variables: percentage of individuals: 1 ) below the poverty line; 2) unemployed; 3) median household income; 4) foreign-born; and 5) with less than a high school education. ${ }^{11-13}$

\section{Statistical analysis}

Continuous variables were reported using medians and interquartile ranges (IQR). Categorical variables were reported using frequency counts and proportions and were compared using the Chi-squared test. Predictors of deferred therapy and decision for RP vs. definitive RT were each evaluated using univariable and multivariable logistic regression analyses. All of the aforementioned oncological and sociodemographic variables, operationalized as categorical variables, were included a priori in the multivariable analyses to control for potential sources of confounding. The variance inflation factor test was used to test for variable multicollinearity. A cutoff value of five was used to exclude variables on the basis of a high degree of multicollinearity. The Cuzick's test for trend, an extension of the Wilcoxon rank-sum test, ${ }^{14}$ was used to evaluate trends in AS uptake by year for each FIR group. A $p<0.05$ denoted statistical significance. $R$ version 4.0.3 (The R Foundation for Statistical Computing, Vienna, Austria) was used to perform all statistical analyses.

\section{Results}

Of 357140 men with PCa in the SEER WW database, we identified 20334 men with NCCN FIR PCa who were managed with AS for at least one year following diagnosis. Of these 20334 men, 9224 (45.4\%), 2552 (12.6\%), and 8558 (42.1\%) were in the GG2, PSA $10-20 \mathrm{ng} / \mathrm{ml}$, and cT2bc groups, respectively (Fig. 1). Baseline sociodemographic and oncological characteristics for the overall cohort and by FIR group are presented in Table 1. Median age at diagno- 


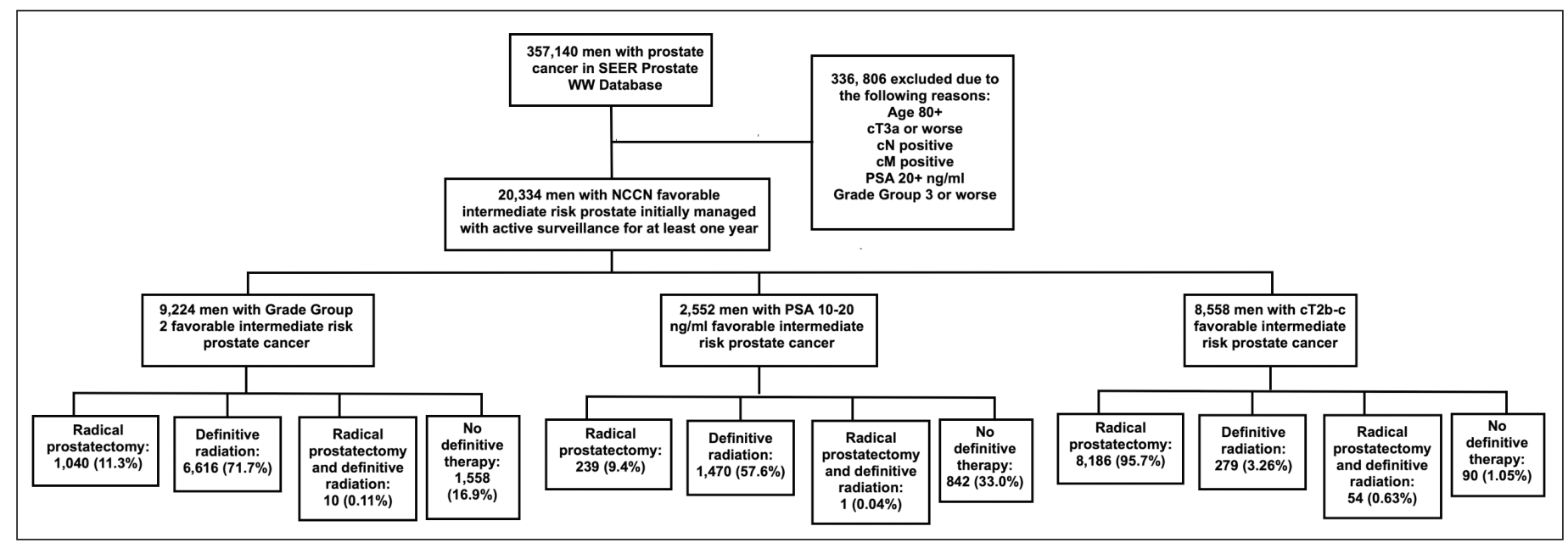

Fig.1. Study flow chart. PSA: prostate-specific antigen; SEER: Surveillance, Epidemiology, and End Results. WW: watchful waiting

sis was 64.0 years (IQR 58.0-69.0). Caucasian and African American patients accounted for 14182 (69.7\%) and 3344 (16.4\%) patients, respectively. Median serum PSA level at diagnosis was $5.60 \mathrm{ng} / \mathrm{ml}$ and median percent positive cores was $21.4 \%$ (IQR $12.5-33.3 \%$ ) (Table 1).

A total of 4061 patients $(20.0 \%$ of all patients in the study cohort) were diagnosed in 2010; this figure decreased to $2947(14.55 \%)$ in 2015 ( $p$ for trend <0.001). Of the 20334 patients in the cohort, 17895 (88.0\%) eventually underwent deferred definitive therapy with either RP and/or RT. The corresponding figures in the GG2, PSA $10-20 \mathrm{ng} / \mathrm{ml}$, and cT2b-c groups were 7666 (83.1\%), $1710(67.0 \%)$, and 8519 (99.5\%), respectively ( $p<0.001)$. Of the 7666 and 1710 patients in the GG2 and PSA $10-20 \mathrm{ng} / \mathrm{ml}$ groups, respectively, definitive RT was the treatment of choice in 6616 $(86.3 \%)$ and $1470(86.0 \%)$ patients, respectively. Conversely, 8186 patients ( $96.1 \%$ of treated patients) in the cT2b-c group opted for RP ( $p$ across FIR groups $<0.001$ ).

Predictors of undergoing deferred therapy on univariable logistic regression analyses are presented in Supplementary Table 1 (available at cuaj.ca). On multivariable analysis, baseline oncological variables predicting increased odds of deferred intervention included higher volume disease on biopsy/TURP specimens in the GG2 and PSA 10-20 ng/ml groups (odds ratio [OR] for $37.6-49.9 \%$ vs $0-12.5 \%$ : 1.33 and 2.10, $p=0.008$ and $p<0.001$, respectively) and more advanced clinical stage in all three FIR groups (OR 3.00 and 5.26 for cT2a vs. cT1, $\mathrm{p}<0.001$ in the GG2 and PSA $10-20$ $\mathrm{ng} / \mathrm{ml}$ groups, respectively; OR 15.5 for cT2c vs. cT2b in the cT2b-c group, $\mathrm{p}<0.001$ ).

With regards to baseline sociodemographic variables, patients of higher SES were significantly more likely to undergo definitive therapy in all three FIR groups (ORs for highest vs. lowest quartiles: $1.72,1.50$, and $1.60, p<0.001$, $\mathrm{p}=0.013$, and $\mathrm{p}=0.03$, for the GG2, PSA $10-20 \mathrm{ng} / \mathrm{ml}$, and cT2b-c groups, respectively). In the GG2 group, African
American patients (vs. Caucasian, OR 0.83, p=0.03) and those diagnosed in a Western region (vs. Northeastern, OR $0.81, p=0.014$ ) had significantly lower odds of undergoing definitive therapy, whereas patients who were not married were significantly more likely to opt for definitive therapy (OR 1.43, p<0.001). In the cT2b-c group, older patients (OR for 70-79 vs. 30-49: 0.16, $\mathrm{p}=0.004$ ), those who were uninsured (vs. insured, OR 0.18, $\mathrm{p}=0.009$ ), and those diagnosed in a Southeastern region (vs. Northeastern, OR 0.42, $p=0.022$ ) all had significantly lower odds of undergoing definitive therapy (Table 2).

Among patients who underwent deferred definitive therapy, patients with larger tumor volume at time of diagnosis were significantly more likely to opt for definitive RT over $\mathrm{RP}$ in all FIR groups (OR for $37.6-49.9 \%$ vs. $0-12.5 \%$ : 0.34 , 0.21 , and $0.33, p<0.001, p=0.014$, and $p<0.001$ for the GG2, PSA 10-20 ng/ml, and cT2b-c groups, respectively). Conversely, patients with a more advanced clinical stage were significantly more likely to opt for RP (OR 167.2 and 239.8 for cT2a vs. cT1, $\mathrm{p}<0.001$ in the GG2 and PSA 10-20 $\mathrm{ng} / \mathrm{ml}$ groups, respectively, and OR 38.6 for cT2c vs. cT2b in the $\mathrm{cT} 2 \mathrm{~b}-\mathrm{c}$ group, $\mathrm{p}<0.001)$. In the GG2 group, patients with a PSA of 5-10 ng/ml (OR 1.60, $\mathrm{p}=0.033)$ and no prior non-PCa malignancy (OR 1.60, $\mathrm{p}=0.033$ ) were both significantly more likely to opt for RP over definitive RT. With regards to sociodemographic variables, older patients (ORs for 70-79 vs. 30-49: 0.034 and 0.027, $\mathrm{p}<0.001$ for the GG2 and cT2b-c groups, respectively) and those of higher SES in the GG2 (OR for second vs. lowest: 0.63, p=0.013) and cT2b-c groups (OR for third vs. lowest: $0.32, p=0.034$ ) were significantly more likely to choose RT over RP. Similarly, African American patients in the GG2 and PSA 10-20 ng/ml groups were significantly more likely to undergo XRT (OR vs. Caucasian: 0.58 and $0.34, p=0.003$ and $p=0.012$, respectively). Conversely, patients who were not married were significantly more likely to undergo RP vs. RT in the GG2 
Sayyid et al

\begin{tabular}{|c|c|c|c|c|}
\hline Variable & $\begin{array}{l}\text { Overall favorable } \\
\text { intermediate-risk } \\
\text { cohort ( } n=20334 \text { ) }\end{array}$ & $\begin{array}{l}\text { GG2 favorable } \\
\text { intermediate-risk } \\
\text { cohort }(n=9224)\end{array}$ & $\begin{array}{l}\text { PSA } 10-20 \mathrm{ng} / \mathrm{ml} \\
\text { favorable intermediate- } \\
\text { risk cohort ( } \mathrm{n}=2552)\end{array}$ & $\begin{array}{c}\text { cT2b-c favorable } \\
\text { intermediate-risk } \\
\text { cohort }(n=8558)\end{array}$ \\
\hline \multicolumn{5}{|l|}{ Year of diagnosis } \\
\hline 2010 & $4061(20.0 \%)$ & 1454 (15.8\%) & 502 (19.7\%) & $2105(24.6 \%)$ \\
\hline 2011 & $3707(18.2 \%)$ & $1438(15.6 \%)$ & $466(18.3 \%)$ & $1803(21.1 \%)$ \\
\hline 2012 & $3603(17.7 \%)$ & $1651(17.9 \%)$ & $435(17.0 \%)$ & $1517(17.7 \%)$ \\
\hline 2013 & $3163(15.6 \%)$ & $1547(16.8 \%)$ & $409(16.0 \%)$ & $1207(14.1 \%)$ \\
\hline 2014 & $2853(14.0 \%)$ & $1459(15.8 \%)$ & $379(14.9 \%)$ & $1015(11.9 \%)$ \\
\hline 2015 & $2947(14.55 \%)$ & 1675 (18.2\%) & $361(14.1 \%)$ & $911(10.6 \%)$ \\
\hline Age at diagnosis, median (IQR) & $64.0(58.0-69.0)$ & $66.0(61.0-71.0)$ & $67.0(61.0-72.0)$ & $60.0(55.0-65.0)$ \\
\hline \multicolumn{5}{|l|}{ Race } \\
\hline Caucasian & $14182(69.7 \%)$ & $6302(68.3 \%)$ & $1590(52.3 \%)$ & $6290(73.5 \%)$ \\
\hline African American & $3344(16.4 \%)$ & $1772(19.2 \%)$ & $473(18.5 \%)$ & $1099(12.8 \%)$ \\
\hline Hispanic & $1567(7.71 \%)$ & $590(6.40 \%)$ & $252(9.87 \%)$ & 725 (8.47\%) \\
\hline Asia/Pacific Islander & $864(4.25 \%)$ & 367 (3.98\%) & $166(6.50 \%)$ & $331(3.87 \%)$ \\
\hline American Indian/Alaska Native & $68(0.33 \%)$ & $31(0.34 \%)$ & $8(0.31 \%)$ & $29(0.34 \%)$ \\
\hline Unknown & $309(1.52 \%)$ & $162(1.76 \%)$ & $63(2.47 \%)$ & $84(0.98 \%)$ \\
\hline \multicolumn{5}{|l|}{ Marital status } \\
\hline Married & $14173(69.7 \%)$ & 6046 (65.5\%) & 1548 (60.7\%) & 6579 (76.9\%) \\
\hline Not married & $4144(20.4 \%)$ & $2105(22.8 \%)$ & $631(24.7 \%)$ & $1408(16.5 \%)$ \\
\hline Unknown & 2017 (9.9\%) & $1073(11.6 \%)$ & $373(14.6 \%)$ & $571(6.67 \%)$ \\
\hline \multicolumn{5}{|l|}{ SEER registry } \\
\hline New Jersey & $2816(13.8 \%)$ & $1361(14.7 \%)$ & $295(11.6 \%)$ & $1160(13.6 \%)$ \\
\hline San Francisco- Oakland & $1123(5.52 \%)$ & $559(6.06 \%)$ & $196(7.68 \%)$ & $368(4.30 \%)$ \\
\hline Los Angeles & $1142(5.62 \%)$ & $374(4.05 \%)$ & $146(5.72 \%)$ & $622(7.27 \%)$ \\
\hline Louisiana & $1106(5.44 \%)$ & $503(5.45 \%)$ & $139(5.45 \%)$ & $464(5.42 \%)$ \\
\hline Connecticut & 982 (4.83\%) & $506(5.49 \%)$ & $102(4.00 \%)$ & 374 (4.37\%) \\
\hline Detroit (metropolitan) & $1709(8.40 \%)$ & $1044(11.3 \%)$ & $119(4.66 \%)$ & $546(6.38 \%)$ \\
\hline Seattle (Puget Sound) & 1071 (5.27\%) & $470(5.10 \%)$ & $98(3.84 \%)$ & $503(5.88 \%)$ \\
\hline Rural Georgia & $53(0.26 \%)$ & $30(0.33 \%)$ & $12(0.47 \%)$ & $11(0.13 \%)$ \\
\hline Atlanta (metropolitan) & 801 (3.94\%) & $504(5.46 \%)$ & 101 (4.0\%) & $196(2.29 \%)$ \\
\hline California (excluding SF/SJM/LA) & $4052(19.9 \%)$ & $1556(16.9 \%)$ & $650(25.5 \%)$ & $1846(21.6 \%)$ \\
\hline Greater Georgia & $1828(9.0 \%)$ & $963(10.4 \%)$ & $237(9.29 \%)$ & $628(7.34 \%)$ \\
\hline Kentucky & $1235(6.07 \%)$ & $398(4.31 \%)$ & $140(5.49 \%)$ & $697(8.14 \%)$ \\
\hline San Jose-Monterey & $725(3.57 \%)$ & $327(3.55 \%)$ & $123(4.82 \%)$ & $275(3.21 \%)$ \\
\hline Utah & $511(2.51 \%)$ & $189(2.05 \%)$ & $36(1.41 \%)$ & $286(3.34 \%)$ \\
\hline Hawaii & $271(1.33 \%)$ & $107(1.16 \%)$ & $41(1.61 \%)$ & $123(1.44 \%)$ \\
\hline lowa & $584(2.87 \%)$ & $233(2.53 \%)$ & $62(2.43 \%)$ & 289 (3.38\%) \\
\hline New Mexico & $321(1.58 \%)$ & $100(1.08 \%)$ & $54(2.12 \%)$ & $167(1.95 \%)$ \\
\hline Alaska Natives & $4(0.02 \%)$ & $0(0.0 \%)$ & $1(0.04 \%)$ & $3(0.035 \%)$ \\
\hline \multicolumn{5}{|l|}{ Insurance status } \\
\hline Insured & $18239(89.7 \%)$ & $8074(87.5)$ & $2106(82.5 \%)$ & $8059(94.2 \%)$ \\
\hline Uninsured & $212(1.04 \%)$ & $86(0.93 \%)$ & $52(2.04 \%)$ & 74 (0.86\%) \\
\hline Medicaid & $681(3.35 \%)$ & $318(3.45 \%)$ & $150(5.88 \%)$ & $213(2.49 \%)$ \\
\hline Unknown & $1202(5.91 \%)$ & $746(8.09 \%)$ & $244(9.56 \%)$ & $212(2.48 \%)$ \\
\hline \multicolumn{5}{|l|}{ Socioeconomic status } \\
\hline 1 (lowest) & $4620(22.7 \%)$ & $1991(21.6 \%)$ & $664(26.0 \%)$ & $1965(23.0 \%)$ \\
\hline 2 & $4580(22.5 \%)$ & $2055(22.3 \%)$ & $656(25.7 \%)$ & 1869 (21.8\%) \\
\hline 3 & $5724(28.1 \%)$ & $2674(29.0 \%)$ & $691(27.1 \%)$ & $2359(27.6 \%)$ \\
\hline 4 (highest) & $5410(26.6 \%)$ & $2504(27.1 \%)$ & $541(21.2 \%)$ & $2365(27.6 \%)$ \\
\hline
\end{tabular}




\begin{tabular}{|c|c|c|c|c|}
\hline Variable & $\begin{array}{l}\text { Overall favorable } \\
\text { intermediate-risk } \\
\text { cohort }(n=20334)\end{array}$ & $\begin{array}{c}\text { GG2 favorable } \\
\text { intermediate-risk } \\
\text { cohort }(n=9224)\end{array}$ & $\begin{array}{l}\text { PSA } 10-20 \mathrm{ng} / \mathrm{ml} \\
\text { favorable intermediate- } \\
\text { risk cohort ( } \mathrm{n}=2552)\end{array}$ & $\begin{array}{c}\text { cT2b-c favorable } \\
\text { intermediate-risk } \\
\text { cohort }(n=8558)\end{array}$ \\
\hline PSA at diagnosis, median (IQR) & $5.60(4.40-7.70)$ & $5.60(4.50-7.10)$ & $12.30(10.90-14.60)$ & $5.00(4.10-6.30)$ \\
\hline Percent cores positive, median (IQR) & $21.4(12.5-33.3)$ & $25.0(16.7-33.3)$ & $16.7(8.33-25.0)$ & $18.8(11.1-33.3)$ \\
\hline \multicolumn{5}{|l|}{ cT Stage } \\
\hline cT1 & $9603(47.2 \%)$ & $7383(80.0 \%)$ & $2220(87.0 \%)$ & $0(0.0 \%)$ \\
\hline cT2a & $2173(10.7 \%)$ & $1841(20.0 \%)$ & $332(13.0 \%)$ & $0(0.0 \%)$ \\
\hline $\mathrm{cT} 2 \mathrm{~b}$ & $373(1.83 \%)$ & $0(0.0 \%)$ & 0 & $373(4.36 \%)$ \\
\hline cT2c & $8185(40.3 \%)$ & $0(0.0 \%)$ & 0 & $8185(95.6 \%)$ \\
\hline \multicolumn{5}{|l|}{ Prostate cancer as first diagnosed malignancy } \\
\hline Yes & $19046(93.7 \%)$ & $8543(92.6 \%)$ & $2364(92.6 \%)$ & $8139(95.1 \%)$ \\
\hline No (i.e., previous, non-prostate cancer diagnosis) & $1288(6.33 \%)$ & 681 (7.38\%) & 188 (7.37\%) & 419 (4.90\%) \\
\hline
\end{tabular}

(OR 1.39, $\mathrm{p}=0.016)$ and cT2b-c groups (OR 2.45, $\mathrm{p}<0.001$ ) (Table 3) (Supplementary Table 2; available at cuaj.ca).

\section{Discussion}

In this population-based analysis of 20334 men with FIR PCa managed with AS for at least one year following diagnosis, we determined that most $(88.0 \%)$ patients eventually discontinued AS in favor of deferred definitive therapy. This figure is significantly higher than that previously reported for low-risk PCa patients from the SEER WW database $(65.7 \%) .{ }^{15}$ It is also higher than the proportion treated in a recent, single-center experience of AS in intermediate-risk cancer, where it was $49 \%$ at 10 years. ${ }^{16}$ Notably, choice of deferred definitive therapy differed by FIR risk group in our cohort. RT was the treatment of choice for patients with GG2 and PSA $10-20 \mathrm{ng} / \mathrm{ml} \mathrm{FIR} \mathrm{PCa}(86.3 \%$ and $86.0 \%$, respectively), whereas RP was the treatment of choice for $96.1 \%$ of patients with cT2b-c FIR PCa.

A significant annual decrease in number of FIR PCa patients managed with AS was observed for the overall cohort, which was secondary to an absolute decrease in number of PSA 10-20 ng/ml and CT2b-c FIR patients managed with AS. There was a concurrent increase in the number of GG2 FIR patients managed with AS. Despite this overall decrease, it is not possible to infer that there has been a decreased uptake of AS for FIR patients without considering the number of such patients managed with definitive therapy during the same timeframe. This decrease may, in part, reflect the overall decrease in PCa incidence following the 2012 United States Preventive Services Task Force recommendations. ${ }^{17}$

Advanced clinical stage was consistently found to be strongly associated with increased odds of undergoing deferred definitive intervention, and among those who underwent intervention, higher rates of RP over RT (ORs of 38.6-239.8 across all three FIR groups). These findings may be related to the increased uptake of multiparametric magnetic resonance imaging (mpMRI) in the followup of AS patients since 2010, resulting in increased detection of extraprostatic extension. ${ }^{18}$ This would plausibly trigger discontinuation of AS and may also explain the decrease in numbers of cT2b-c FIR patients managed with AS between 2010 and 2015 in our cohort.

Patients of higher SES were significantly more likely to undergo deferred definitive therapy across FIR subgroups. Patients of higher SES are known to be more likely to follow up with their physicians, ${ }^{19,20}$ and thus be more compliant with repeat PSA, clinical exam, and biopsy protocols. This increases the likelihood of detecting signs of disease progression/understaging, which act as triggers for intervention. Interestingly, such patients were also more likely to opt for definitive RT over $\mathrm{RP}$ in two of the FIR groups. Similarly, FIR African American patients with GG2 or PSA $10-20 \mathrm{ng} / \mathrm{ml}$ were more likely to opt definitive RT over RP, even after controlling for baseline oncological and sociodemographic variables, such as SES and insurance status. These findings may reflect African American patients' known distrust of the medical system ${ }^{21-23}$ and their desire to avoid invasive interventions. This is further reflected in GG2 FIR African American patients being 17\% less likely to undergo definitive intervention.

This is the first population-based study evaluating sociodemographic and oncological predictors of deferred definitive therapy in AS FIR PCa patients. Our study is strengthened by our use of a large, validated, ${ }^{24,25}$ nationally representative dataset. ${ }^{9}$ It is important to note, however, that our deferred intervention rate of $88.0 \%$ is significantly higher than those previously reported in other series, which have ranged from $31-49 \%$ over a $5-10$-year followup period. ${ }^{16,26-28}$ This difference is likely related in part to differences in cohort eligibility criteria, with previously reported series applying stricter eligibility criteria. In these series, AS was often restricted to FIR patients older than 65 years $^{26,28}$ or a life expectancy less than 10 years. ${ }^{28}$ Furthermore, these series originated 


\begin{tabular}{|c|c|c|c|c|c|c|c|c|c|}
\hline \multirow[b]{2}{*}{ Variable } & \multicolumn{3}{|c|}{$\begin{array}{c}\text { GG2 favorable } \\
\text { intermediate-risk cohort } \\
(n=9224)\end{array}$} & \multicolumn{3}{|c|}{$\begin{array}{l}\text { PSA 10-20 ng/ml favorable } \\
\text { intermediate-risk cohort } \\
(n=2552)\end{array}$} & \multicolumn{3}{|c|}{$\begin{array}{c}\text { cT2b-c favorable } \\
\text { intermediate-risk cohort } \\
(\mathrm{n}=8558)\end{array}$} \\
\hline & OR & $95 \% \mathrm{Cl}$ & $\mathbf{p}$ & OR & $95 \% \mathrm{Cl}$ & $\mathbf{p}$ & OR & $95 \% \mathrm{Cl}$ & $\mathbf{p}$ \\
\hline \multicolumn{10}{|l|}{ Year of diagnosis (reference: $2010-11$ ) } \\
\hline $2012-13$ & 0.88 & $0.75-1.03$ & 0.12 & 0.80 & $0.64-1.02$ & 0.071 & 0.45 & $0.25-0.78$ & 0.005 \\
\hline 2014-15 & 0.89 & $0.75-1.04$ & 0.14 & 0.76 & $0.59-0.97$ & 0.028 & 0.64 & $0.33-1.22$ & 0.17 \\
\hline \multicolumn{10}{|l|}{ Age at diagnosis (reference: $30-49$ years) } \\
\hline $50-59$ & 1.22 & $0.75-1.91$ & 0.40 & 0.91 & $0.27-2.66$ & 0.87 & 1.17 & $0.26-3.68$ & 0.81 \\
\hline $60-69$ & 1.43 & $0.89-2.20$ & 0.12 & 1.08 & $0.33-3.10$ & 0.90 & 0.44 & $0.10-1.25$ & 0.18 \\
\hline $70-79$ & 1.30 & $0.81-2.03$ & 0.26 & 0.88 & $0.27-2.54$ & 0.82 & 0.16 & $0.036-0.50$ & 0.004 \\
\hline \multicolumn{10}{|l|}{ Race (reference: Caucasian) } \\
\hline African American & 0.83 & $0.70-0.98$ & 0.03 & 0.85 & $0.65-1.13$ & 0.27 & 0.69 & $0.36-1.43$ & 0.29 \\
\hline Hispanic & 0.97 & $0.75-1.28$ & 0.85 & 0.96 & $0.68-1.36$ & 0.83 & 0.61 & $0.29-1.38$ & 0.20 \\
\hline $\begin{array}{l}\text { Asia/Pacific Islander/American Indian/ } \\
\text { Alaska Native }\end{array}$ & 0.94 & $0.69-1.30$ & 0.69 & 0.95 & $0.64-1.43$ & 0.81 & 2.86 & $0.57-52.2$ & 0.31 \\
\hline \multicolumn{10}{|l|}{ Insurance status (reference: Insured) } \\
\hline Uninsured & 0.58 & $0.39-1.11$ & 0.096 & 0.59 & $0.32-1.12$ & 0.10 & 0.18 & $0.058-0.82$ & 0.009 \\
\hline Medicaid & 0.88 & $0.65-1.20$ & 0.40 & 0.78 & $0.53-1.17$ & 0.23 & 0.72 & $0.27-2.52$ & 0.55 \\
\hline \multicolumn{10}{|l|}{ Marital status (reference: married) } \\
\hline Not married & 1.43 & $1.24-1.65$ & $<0.001$ & 1.17 & $0.94-1.46$ & 0.16 & 1.61 & $0.91-2.76$ & 0.087 \\
\hline \multicolumn{10}{|l|}{$\begin{array}{l}\text { SEER registry region (reference: } \\
\text { Northeast) }\end{array}$} \\
\hline Southeast & 1.10 & $0.91-1.34$ & 0.31 & 1.15 & $0.82-1.60$ & 0.43 & 0.42 & $0.20-0.87$ & 0.022 \\
\hline Midwest & 1.21 & $0.86-1.73$ & 0.28 & 1.00 & $0.62-1.63$ & 1.00 & 0.79 & $0.28-2.56$ & 0.66 \\
\hline West & 0.81 & $0.68-0.96$ & 0.014 & 0.76 & $0.57-1.02$ & 0.068 & 0.79 & $0.38-1.60$ & 0.53 \\
\hline \multicolumn{10}{|l|}{ SES quartiles (reference: 1 [lowest]) } \\
\hline 2 & 1.30 & $1.08-1.57$ & $<0.001$ & 1.26 & $0.95-1.67$ & 0.11 & 1.78 & $0.89-3.68$ & 0.11 \\
\hline 3 & 1.11 & $0.93-1.32$ & 0.24 & 1.07 & $0.81-1.41$ & 0.64 & 0.93 & $0.50-1.72$ & 0.83 \\
\hline 4 (highest) & 1.72 & $1.41-2.10$ & $<0.001$ & 1.50 & $1.09-2.08$ & 0.013 & 1.60 & $1.12-3.52$ & 0.03 \\
\hline $\mathrm{PCa}$ as first cancer diagnosis (reference: & 1.20 & $0.95-1.52$ & 0.12 & 1.46 & $1.01-2.09$ & 0.042 & 0.50 & $0.12-1.45$ & 0.27 \\
\hline
\end{tabular}
previously diagnosed with other cancer) PSA (references: $0-5 \mathrm{ng} / \mathrm{ml}$ for groups 1 and $3 ; 10-15 \mathrm{ng} / \mathrm{ml}$ for group 2)

$$
\text { 5-10 ng/ml }
$$

Percent cores positive (reference: 0-12.5\%)

$12.6-25.0 \%$
$25.1-37.5 \%$
$37.6-49.9 \%$

cT stage (cT1 as reference for groups 1 and; cT2b for group 3)

$$
\text { cT2a }
$$$$
\text { cT2c }
$$
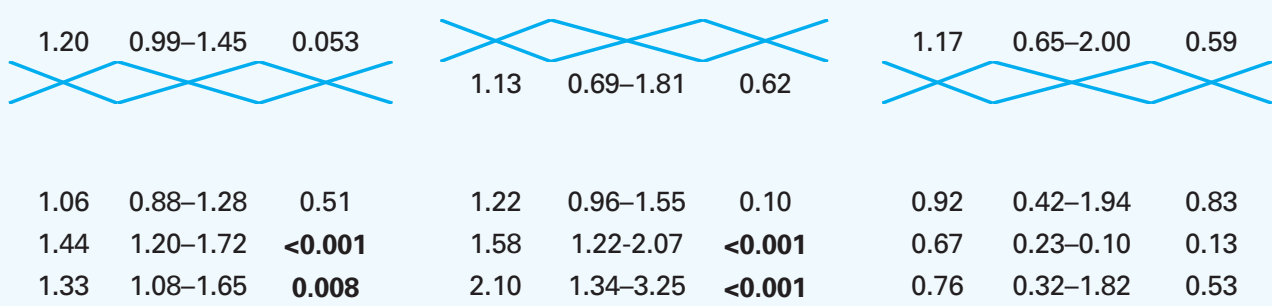

$\begin{array}{ccc}1.22 & 0.96-1.55 & 0.10 \\ 1.58 & 1.22-2.07 & <0.001 \\ 2.10 & 1.34-3.25 & <0.001\end{array}$

.


Table 3. Predictors of receiving radical prostatectomy vs. radiation therapy on multivariable logistic regression analysis for favorable intermediate prostate cancer patients by group

\begin{tabular}{|c|c|c|c|c|c|c|c|c|c|}
\hline \multirow[b]{2}{*}{ Variable } & \multicolumn{3}{|c|}{$\begin{array}{l}\text { GG2 favorable intermediate- } \\
\text { risk cohort }(n=9224)\end{array}$} & \multicolumn{3}{|c|}{$\begin{array}{l}\text { PSA } 10-20 \mathrm{ng} / \mathrm{ml} \text { favorable } \\
\text { intermediate-risk cohort } \\
\qquad(\mathrm{n}=2552)\end{array}$} & \multicolumn{3}{|c|}{$\begin{array}{c}\text { cT2b-c favorable } \\
\text { intermediate-risk cohort } \\
(n=8558)\end{array}$} \\
\hline & OR & $95 \% \mathrm{Cl}$ & $\mathbf{p}$ & OR & $95 \% \mathrm{Cl}$ & $\mathbf{p}$ & OR & $95 \% \mathrm{Cl}$ & $\mathbf{p}$ \\
\hline \multicolumn{10}{|l|}{ Year of diagnosis (reference: $2010-11$ ) } \\
\hline $2012-13$ & 0.96 & $0.74-1.25$ & 0.75 & 1.47 & $0.79-2.75$ & 0.23 & 1.05 & $0.72-1.54$ & 0.80 \\
\hline 2014-15 & 1.03 & $0.79-1.34$ & 0.83 & 1.46 & $0.76-2.86$ & 0.26 & 1.29 & $0.84-2.03$ & 0.25 \\
\hline \multicolumn{10}{|l|}{$\begin{array}{l}\text { Age at diagnosis (reference: } 30-49 \\
\text { years) }\end{array}$} \\
\hline $50-59$ & 0.42 & $0.20-0.88$ & 0.025 & 0.46 & $0.04-5.34$ & 0.56 & 0.48 & $0.11-1.45$ & 0.25 \\
\hline $60-69$ & 0.12 & $0.059-0.25$ & $<0.001$ & 0.40 & $0.040-4.50$ & 0.49 & 0.12 & $0.028-0.34$ & $<0.001$ \\
\hline $70-79$ & 0.034 & $0.015-0.071$ & $<0.001$ & 0.12 & $0.010-1.37$ & 0.11 & 0.027 & $0.006-0.082$ & $<0.001$ \\
\hline \multicolumn{10}{|l|}{ Race (reference: Caucasian) } \\
\hline African American & 0.58 & $0.41-0.83$ & 0.003 & 0.34 & $0.14-0.78$ & 0.012 & 0.69 & $0.41-1.19$ & 0.16 \\
\hline Hispanic & 1.15 & $0.75-1.77$ & 0.54 & 0.76 & $0.33-1.75$ & 0.51 & 0.96 & $0.49-2.02$ & 0.90 \\
\hline $\begin{array}{l}\text { Asia/Pacific Islander/American Indian/ } \\
\text { Alaska Native }\end{array}$ & 0.96 & $0.59-1.57$ & 0.88 & 0.62 & $0.23-1.72$ & 0.36 & 0.54 & $0.27-1.19$ & 0.10 \\
\hline \multicolumn{10}{|l|}{ Insurance status (reference: insured) } \\
\hline Uninsured & 1.50 & $0.45-4.83$ & 0.51 & 1.37 & $0.16-9.18$ & 0.77 & 0.87 & $0.18-15.6$ & 0.89 \\
\hline Medicaid & 0.56 & $0.28-1.08$ & 0.087 & 0.62 & $0.18-2.11$ & 0.44 & 0.78 & $0.36-1.88$ & 0.56 \\
\hline \multicolumn{10}{|l|}{ Marital status (reference: married) } \\
\hline Not married & 1.39 & $1.06-1.81$ & 0.016 & 0.84 & $0.46-1.53$ & 0.57 & 2.45 & $1.67-3.57$ & $<0.001$ \\
\hline \multicolumn{10}{|l|}{$\begin{array}{l}\text { SEER registry region (reference: } \\
\text { Northeast) }\end{array}$} \\
\hline Southeast & 1.38 & $0.98-1.94$ & 0.069 & 1.16 & $0.46-2.94$ & 0.76 & 0.71 & $0.42-1.17$ & 0.18 \\
\hline Midwest & 1.36 & $0.91-2.03$ & 0.14 & 1.33 & $0.42-4.17$ & 0.63 & 0.81 & $0.42-1.63$ & 0.54 \\
\hline West & 1.09 & $0.82-1.45$ & 0.54 & 0.82 & $0.37-1.80$ & 0.62 & 1.07 & $0.66-1.71$ & 0.79 \\
\hline \multicolumn{10}{|l|}{ SES quartiles (reference: 1 [lowest]) } \\
\hline 2 & 0.63 & $0.44-0.91$ & 0.013 & 0.81 & $0.37-1.78$ & 0.60 & 1.11 & $0.66-1.89$ & 0.70 \\
\hline 3 & 0.78 & $0.57-1.08$ & 0.13 & 0.68 & $0.32-1.44$ & 0.32 & 0.61 & $0.38-0.96$ & 0.034 \\
\hline 4 (highest) & 0.74 & $0.53-1.04$ & 0.084 & 0.46 & $0.20-1.00$ & 0.052 & 1.00 & $0.59-1.69$ & 1.00 \\
\hline PCa as first cancer diagnosis & 1.60 & $1.04-2.46$ & 0.033 & 0.97 & $0.33-2.90$ & 0.96 & 1.61 & $0.88-2.79$ & 0.10 \\
\hline
\end{tabular}

(reference: previously diagnosed with other cancer)

PSA (references: $0-5 \mathrm{ng} / \mathrm{ml}$ for groups

1 and $3 ; 10-15 \mathrm{ng} / \mathrm{ml}$ for group 2)

$5-10 \mathrm{ng} / \mathrm{ml}$

$10-20 \mathrm{ng} / \mathrm{ml}$

Percent cores positive (reference: $0-12.5 \%$

$\begin{array}{rccccccccc}12.6-25.0 \% & 0.77 & 0.57-1.05 & 0.10 & 0.69 & 0.37-1.29 & 0.25 & 0.74 & 0.42-1.26 & 0.27 \\ 25.1-37.5 \% & 0.51 & 0.38-0.69 & <0.001 & 0.42 & 0.20-0.85 & \mathbf{0 . 0 1 7} & 0.33 & 0.20-0.54 & <0.001 \\ 37.6-49.9 \% & 0.34 & 0.23-0.48 & <0.001 & 0.21 & 0.058-0.70 & \mathbf{0 . 0 1 4} & 0.33 & 0.18-0.58 & <0.001\end{array}$

cT Stage (cT1 as reference for groups 1 and 2; cT2b for group 3)

cT2a
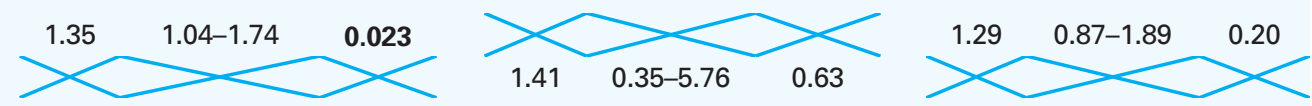

cT2c

Practice patterns have also evolved since the study time period of 2010-2015. There has been an increased uptake of $\mathrm{mpMR}^{29}$ and prognostic genetic biomarkers ${ }^{30}$ in the AS setting, as well as changes to the GS scoring system. ${ }^{31}$ Thus, the results of this study must be interpreted in light of these recent advances.

Further limitations to this study include the absence of timing of interventions, which precluded us from performing 
time-to-event analyses with Cox proportional hazard modeling, and inability to differentiate patients initially managed with AS or WW. However, by excluding patients older than 80 years at time of diagnosis, we attempted to minimize the number of patients in the WW group. ${ }^{10}$ Similar to other studies originating from population-based registries, this analysis is subject to the limitations and inherent biases characteristic of population-based registries, particularly with regards to missing data, which has been found to be as high as $46 \%$ in validation studies of this dataset. ${ }^{24,25}$ Patients in the SEER database are from population-based cancer registries covering approximately $35 \%$ of the U.S. population, and thus results from this dataset may not be generalizable to the entire U.S. population. ${ }^{9}$

\section{Conclusions}

Most FIR PCa patients initially managed with AS eventually undergo deferred definitive therapy, with choice of treatment significantly influenced by patients' baseline oncological and sociodemographic characteristics.

Competing interests: The authors do not report any competing personal or financial interests related to this work.

This paper has been peer-reviewed.

\section{References}

1. Mottet N, van den Bergh RCN, Briers E, et al. EAU-EANM-ESTRO-ESUR-SIOG guidelines on prostate cancer-2020 update. Part 1: Screening, diagnosis, and local treatment with curative intent. Eur Urol 2021;79:242-62. https://doi.org/10.1016/i.eururo.2020.09.042

2. Sanda MG, Cadeddu JA, Kirkby E, et al. Clinically localized prostate cancer: AUA/ASTRO/SUO guideline. Part 1: Risk stratification, shared decision-making, and care options. J Urol 2018;199:683-90. https://doi.org/10.1016/i.juro.2017.11.095

3. Tosoian JJ, Carter HB, Lepor A, et al. Active surveillance for prostate cancer: Current evidence and contemporary state of practice. Nat Rev Urol 2016;13:205-15. https://doi.org/10.1038/nrurol.2016.45

4. Klotz L, Zhang L, Lam A, et al. Clinical results of long-term followup of a large, active surveillance cohort with localized prostate cancer. J Clin Oncol 2010;28:126-31. https://doi.org/10.1200/JC0.2009.24.2180

5. Hamdy FC, Donovan JL, Lane A, et al. 10-year outcomes after monitoring, surgery, or radiotherapy for localized prostate cancer. N Eng J Med 2016;375:1415-24. https://doi.org/10.1056/NEJMoal 606220

6. Zlotta AR, Egawa S, Pushkar D, et al. Prevalence of prostate cancer on autopsy: Cross-sectional study on unscreened Caucasian and Asian men. J Natl Cancer Inst 2013;105:1050-8. https://doi.org/10.1093/ inci/dip151

7. Mohler JL, Armstrong AJ, Bahnson RR et al. Prostate cancer, version 1.2016. J Natl Compr Canc Netw 2016;14:19-30. https://doi.org/10.6004/inccn.2016.0004

8. Butler SS, Mahal BA, Lamba N, et al. Use and early mortality outcomes of active surveillance in patients with intermediate-risk prostate cancer. Cancer 2019;125:3164-71. https://doi.org/10.1002/cncr.32202

9. NIH. National Cancer Institute: Surveillance, Epidemiology, and End Results Program. Prostate with Watchful Waiting database (2010-2016). Available at: https://seer.cancer.gov/seerstat/databases/prostateww/index.html/. Accessed Jan. 2, 2021.
10. Steinberg $\mathrm{GD}$, Bales $\mathrm{GT}$, Brendler $\mathrm{CB}$. An analysis of watchful waiting for clinically localized prostate cancer. J Urol 1998;159:1431-6. https://doi.org/10.1097/00005392-199805000-00003

11. Chandrasekar T, Klaassen Z, Goldberg H, et al. High competing risks minimize real-world utility of adjuvant targeted therapy in renal cell carcinoma: A population-based analysis. Oncotarget 2018;9:16731-43. https://doi.org/10.18632/oncotarget.24675

12. Chandrasekar T, Klaassen Z, Goldberg H, et al. Metastatic renal cell carcinoma: Patterns and predictors of metastases - a contemporary, population-based series. Urol Oncol 2017;35:661.e7-14. https://doi.org/10.1016/i.urolonc.2017.06.060

13. Sayyid RK, Wilson B, Benton JZ, et al. Upgrading on radical prostatectomy specimens of very low- and low-risk prostate cancer patients on active surveillance: A population-level analysis. Can Urol Assoc J 2021;15:E335-9. hitps://doi.org/10.5489/cuai.6868

14. Cuzick J. A Wilcoxon-type test for trend. Stat Med 1985;4:87-90. https://doi.org/10.1002/ sim. 4780040112

15. Sayyid RK, Klotz L, Benton JZ, et al. Influence of sociodemographic factors on definitive intervention among very low- and low-risk active surveillance patients. Urology 2021;155:117-23. https://doi.org/10.1016/i.urology.2021.01.053

16. Carlsson S, Benfante N, Alvim R, et al. Risk of metastasis in men with grade group 2 prostate cancer managed with active surveillance at a tertiary cancer center. J Urol 2020;203:1117-21. https://doi.org/10.1097/JU.0000000000000742

17. Fleshner K, Carlsson SV, Roobol MJ. The effect of the USPSTF PSA screening recommendation on prostate cancer incidence patterns in the USA. Nat Rev Urol 2017;14:26-37. https://doi.org/10.1038/ nrurol.2016.251

18. Fam MM, Yabes JG, Macleod LC, et al. Increasing utilization of multiparametric magnetic resonance imaging in prostate cancer active surveillance. Urology 2019;130:99-105. https://doi.org/10.1016/i. urology.2019.02.037

19. Olah ME, Gaisano $G$, Hwang SW. The effect of socioeconomic status on access to primary care: An audit study. CMAJ 2013;185:E263-9. https://doi.org/10.1503/cmaj.121383

20. Wong MKY, Wang JT, Czarnecki A, et al. Factors associated with physician followup among patients with chest pain discharged from the emergency department. CMAJ 2015;187:E160-8. https://doi.org/10.1503/cmaj.141294

21. Jacobs EA, Rolle I, Ferrans CE, et al. Understanding African Americans' views of the trustworthiness of physicians. J Gen Intern Med 2006;21:642-7. https://doi.org/10.1111/i.1525-1497.2006.00485.x

22. Rajakumar K, Thomas SB, Musa D, et al. Racial differences in parents' distrust of medicine and research. Arch Pediatr Adolesc Med 2009;163:108-14. https://doi.org/10.1001/archpediatrics.2008.521

23. Corbie-Smith G, Thomas SB, St. George DMM. Distrust, race, and research. Arch Intern Med 2002;162:2458-63. https://doi.org/10.1001/archinte.162.21.2458

24. Jeong CW, Washington SL, Herlemann A, et al. The new Surveillance, Epidemiology, and End Results Prostate with Watchful Waiting database: Opportunities and limitations. Eur Urol 2020;78:335-44. https://doi.org/10.1016/i.eururo.2020.01.009

25. Laviana AA, Luckenbaugh AN, Wallis CJD. Seeking the truth: Understanding the impact of missing data on the validity of the new Surveillance, Epidemiology and End Results Prostate with Watchful Waiting database. Eur Urol 2020178:345-6. https://doi.org/10.1016/i.eururo.2020.01.032

26. Selvadurai ED, Singhera $M$, Thomas K, et al. Medium-term outcomes of active surveillance for localized prostate cancer. Eur Urol 2013;64:981-7. https://doi.org/10.1016/i.eururo.2013.02.020

27. Cooperberg MR, Cowan JE, Hilton JF, et al. Outcomes of active surveillance for men with intermediaterisk prostate cancer. J Clin Oncol 2011;29:228-34. https://doi.org/10.1200/JC0.2010.31.4252

28. Musunuru HB, Yamamoto $\mathrm{T}$, Klotz $\mathrm{L}$, et al. Active surveillance for intermediate-risk prostate cancer: Survival outcomes in the Sunnybrook experience. J Urol 2016;16:1651-8. https://doi.org/10.1016/i. juro.2016.06.102

29. Fam MM, Yabes JG, Macleod LC, et al. Increasing utilization of multiparametric magnetic resonance imaging in prostate cancer active surveillance. Urology 2019;130:99-105. https://doi.org/10.1016/i. urology.2019.02.037

30. Lin DW, Nelson PS. Prognostic genomic biomarkers in patients with localized prostate cancer. JAMA Onco 2021;7:59-60. https://doi.org/10.1001/jamaoncol.2020.6045

31. Swanson GP, Trevathan S, Hammonds KAP, et al. Gleason score evolution and the effect on prostate cancer outcomes. Am J Clin Pathol 2021;155:711-7. https://doi.org/10.1093/aicp/aqaal30

Correspondence: Dr. Zachary Klaassen, Medical College of Georgia at Augusta University, Georgia Cancer Center, Augusta, GA, United States; zklaassen19@gmail.com 